\title{
Intragenomic and intraspecific heterogeneity in rrs may surpass interspecific variability in a natural population of Veillonella
}

\begin{abstract}
Correspondence
Hélène Marchandin

helene.marchandin@univ-

montp1.fr
\end{abstract}

Received 21 January 2010

Revised 7 April 2010

Accepted 15 April 2010

\author{
Anne-Laure Michon, ${ }^{1}$ Fabien Aujoulat, ${ }^{1}$ Laurent Roudière, ${ }^{2}$ Olivier Soulier, ${ }^{1}$ \\ Isabelle Zorgniotti, ${ }^{1}$ Estelle Jumas-Bilak ${ }^{1}$ and Hélène Marchandin ${ }^{1,3}$ \\ ${ }^{1}$ Université Montpellier 1, EA 3755 UM1, Faculté de Pharmacie, 15 Avenue Charles Flahault, \\ BP 14491, 34093 Montpellier Cedex 5, France \\ ${ }^{2}$ Centre Hospitalier Intercommunal de Fréjus-Saint Raphaël, Laboratoire Polyvalent, 240 Avenue de \\ Saint-Lambert, BP 110, 83608 Fréjus Cedex, France \\ ${ }^{3}$ Centre Hospitalier Universitaire de Montpellier, Hôpital Arnaud de Villeneuve, Laboratoire de \\ Bactériologie, 371 Avenue du Doyen Gaston Giraud, 34295 Montpellier Cedex 5, France
}

\begin{abstract}
As well as intraspecific heterogeneity, intragenomic heterogeneity between 16S rRNA gene copies has been described for a range of bacteria. Due to the wide use of 16S rRNA gene sequence analysis for taxonomy, identification and metagenomics, evaluating the extent of these heterogeneities in natural populations is an essential prerequisite. We investigated inter- and intragenomic 16S rRNA gene heterogeneity of the variable region V3 in a population of 149 clinical isolates of Veillonella spp. of human origin and in 13 type or reference Veillonella strains using PCR-temporal temperature gel electrophoresis (TTGE). 16S rRNA gene diversity was high in the studied population, as 45 different banding patterns were observed. Intragenomic heterogeneity was demonstrated for $110(74 \%)$ isolates and 8 (61.5\%) type or reference strains displaying two or three different gene copies. Polymorphic nucleotide positions accounted for $0.5-2.5 \%$ of the sequence and were scattered in helices $\mathrm{H} 16$ and $\mathrm{H} 17$ of the rRNA molecule. Some of them changed the secondary structure of $\mathrm{H} 17$. Phylotaxonomic structure of the population based on the single-copy housekeeping gene rpo $B$ was compared with TTGE patterns. The intragenomic V3 heterogeneity, as well as recombination events between strains or isolates of different $r p o B$ clades, impaired the $16 \mathrm{~S}$ rRNA-based identification for some Veillonella species. Such approaches should be conducted in other bacterial populations to optimize the interpretation of $16 \mathrm{~S}$ rRNA gene sequences in taxonomy and/or diversity studies.
\end{abstract}

\section{INTRODUCTION}

The genus Veillonella currently groups 11 validated species of non-fermentative, strictly anaerobic, Gram-negative cocci. These bacteria belong to the oral, genito-urinary, respiratory and intestinal flora of humans and other animals. Six species, Veillonella dispar, Veillonella parvula, Veillonella atypica, Veillonella montpellierensis, Veillonella

Abbreviations: D2V3, 2D structure type of the $\mathrm{V} 3$ region; $\mathrm{ML}$, maximumlikelihood; TTGE, temporal temperature gradient electrophoresis.

GenBank/EMBL/DDBJ accession numbers for RNA polymerase B subunit $(r p o B)$ genes determined in this work are as follows: VA1VA149, GU479077-GU479225, respectively; V. parvula CIP 60.1, GU479076; V. denticariosi CIP 109449, GU479074; and V. magna DSM $19857^{\top}$, GU479075.

Two supplementary figures, showing the secondary structure of the $16 \mathrm{~S}$ rRNA gene and an ML tree based on partial rpoB sequences, are available with the online version of this paper. rogosae and Veillonella denticariosi have so far been isolated from human flora whilst Veillonella ratti, Veillonella criceti, Veillonella rodentium, Veillonella caviae and Veillonella magna were only reported from non-human animal flora. Species of the genus Veillonella are usually regarded as early colonizers and highly represented members of the human microbiome, particularly in the mouth (Könönen et al., 1999) and the gut (Favier et al., 2002; Zilberstein et al., 2007), and are frequently detected during cultureindependent studies of the diversity of different microbiotae during health and disease (Paster et al., 2001; Wang et al., 2004; Aas et al., 2005; Preza et al., 2008). More frequently isolated from human clinical specimens in aerobic-anaerobic polymicrobial cultures, these bacteria were recovered in pure culture and implicated in severe opportunistic human infections (Bhatti \& Frank, 2000; Marchandin et al., 2001; Boo et al., 2005; Marriott et al., 2007). Molecular studies are required for species identification due to the lack of 
discriminating phenotypic tests. Sequencing of $16 \mathrm{~S}$ rRNA genes ( $16 \mathrm{~S}$ rDNA or $r r s$ ) has proven to be a stable and specific marker for bacterial identification but has failed to discriminate between very related species (Marchandin et al., 2003, 2005), such as $V$. parvula and V. dispar, or V. ratti and $V$. criceti, which shared $99 \%$ of their $16 \mathrm{~S}$ rDNA nucleotide positions. Moreover, intragenomic heterogeneity has been previously demonstrated in a clinical isolate belonging to the genus Veillonella, consisting of $1.43 \%$ divergence between the four rRNA operons $(\mathrm{rrn})$ (Marchandin et al., 2003). An RFLP-PCR-based approach suggested that this phenomenon could be frequent in Veillonella spp. since $74.1 \%$ of the 27 clinical isolates studied produced unexpected restriction patterns compared with type strains (Marchandin et al., 2003). More recently, Byun et al. (2007) reported ambiguous positions observed in the sequencing chromatograms of $V$. denticariosi consistent with intragenomic variations between $16 \mathrm{~S}$ rRNA gene copies.

Although intragenomic heterogeneities between 16S rDNA copies are now well-known for several bacterial species (Ninet et al., 1996; Nübel et al., 1996; Conville \& Witebsky, 2007), their general extent in the natural population remained poorly investigated. The aim of this study was to investigate intragenomic and intergenomic rrs heterogeneity levels in a population of 149 clinical isolates of Veillonella spp. of human origin. To address this point, we validated a PCR-temporal temperature gel electrophoresis (TTGE)-based approach suitable for rapid and convenient $16 \mathrm{~S}$ rRNA gene heterogeneity analysis in such large bacterial populations.

\section{METHODS}

Bacterial strains and isolates, culture conditions and DNA extraction. The study included the type strains of the 11 characterized Veillonella species purchased from the corresponding culture collection ( $r p o B$ gene GenBank accession nos in parentheses): V. atypica ATCC $17744^{\mathrm{T}}$ (EF185159), V. parvula ATCC $10790^{\mathrm{T}}$ (EF185158), V. dispar ATCC $17748^{\mathrm{T}}$ (EF185161), V. ratti ATCC $17746^{\mathrm{T}}$ (EF185165), V. rodentium ATCC $17743^{\mathrm{T}}$ (EF185166), V. criceti ATCC $17747^{\mathrm{T}}$ (EF185164), V. caviae DSM 20738 ${ }^{\mathrm{T}}$ (EF185163), V. rogosae DSM $18960^{\mathrm{T}}$ (EF211831), V. magna DSM $19857^{\mathrm{T}}$ (GU479075), V. montpellierensis CIP $107992^{\mathrm{T}}(\mathrm{EF} 411194)$ and $V$. denticariosi CIP $109448^{\mathrm{T}}$ (EF185162). Reference strains were $V$. parvula CIP 60.1 and $V$. denticariosi CIP 109449 (gifts from Dr Carlier, Institut Pasteur, Paris). One hundred and forty-nine clinical isolates were obtained from the Bacteriology Laboratory of the University Hospital of Montpellier, France, and were designated VA1-VA149. These 149 clinical isolates were collected over an 8 year period (from 1999 to 2007) from diverse clinical samples collected from 140 patients attending various units of the institution. Clinical isolates were recovered in pure culture (seven isolates; VA1, 8, 81, 134 and 144-146, from bone and joint, blood, bronchoalveolar fluid and liver biopsy samples from four patients), in mixed aerobic-anaerobic cultures or in mixed anaerobic cultures (142 isolates from 137 different patients). The sources of these clinical isolates were as follows: respiratory tract including bronchoalveolar fluid $(n=41)$, sinus $(n=3)$, pleural fluid $(n=2)$ and lung biopsy $(n=1)$; skin and soft tissues $(n=42)$; urogenital tract including semen $(n=9)$, amniotic fluid $(n=5)$ and urethral swab $(n=1)$; intraabdominal samples including peritoneal fluid $(n=13)$ and liver biopsy $(n=2)$; bone and joint $(n=5)$; oral cavity $(n=18)$; ear $(n=4)$; blood $(n=1)$; gastric fluid $(n=1)$; and pacemaker $(n=1)$.

Bacteria were cultured on Columbia sheep blood agar (bioMérieux) incubated for 2-5 days in anaerobic jars with the AnaeroGen System (Oxoid). Strictly anaerobic, Gram-negative cocci were identified as Veillonella sp. on the basis of their capacity to reduce nitrate and their susceptibility profile to special-potency disks as previously described (Marchandin et al., 2005). Each strain and isolate was purified by one subculture of a single colony with particular care and frozen at $-80{ }^{\circ} \mathrm{C}$. For subsequent experiments, strains and isolates were cultured in the conditions described above and DNA was extracted using the MasterPure DNA purification kit (EPICENTRE Biotechnologies) according to the recommendations of the manufacturer. DNA yield was quantified by determining $A_{260} / A_{280}$. Extracts were then diluted to a final concentration of $50 \mu \mathrm{g} \mathrm{ml} l^{-1}$.

PCR-TTGE experiment. A 199 bp fragment (from position 338 to position 536, Escherichia coli numbering) overlapping the $16 \mathrm{~S}$ rDNA V3 variable region (position 338 to position 534, E. coli numbering) (Neefs et al., 1993; Sundquist et al., 2007) was amplified using the primers HDA1-GC (primer HDAl with a fragment rich in GC - the 'GC clamp' - added to the 5' extremity) and HDA2 (Ogier et al., 2002). The reaction mixture $(50 \mu \mathrm{l})$ consisted of $200 \mathrm{nM}$ each primer (Sigma Genosys), $200 \mu \mathrm{M}$ each dNTP (Fermentas), $2.5 \mathrm{U}$ FastStart Taq DNA polymerase (Roche) in the appropriate $1 \times$ reaction buffer, with $1.8 \mathrm{mM} \mathrm{MgCl}_{2}$. Template DNA extract (50 ng) was added to the reaction buffer and amplified by thermal cycling as follows: $95{ }^{\circ} \mathrm{C}$ for $2 \mathrm{~min} ; 30$ cycles of $95^{\circ} \mathrm{C}$ for $1 \mathrm{~min}, 6{ }^{\circ} \mathrm{C}$ for $30 \mathrm{~s}, 72{ }^{\circ} \mathrm{C}$ for $1 \mathrm{~min}$; and $72{ }^{\circ} \mathrm{C}$ for $7 \mathrm{~min}$. PCR products were checked by electrophoresis in a $1.5 \%$ agarose gel before TTGE migration in the DCode Universal Mutation Detection System (Bio-Rad Laboratories). Gels $(40 \mathrm{ml})$ were composed of $8 \%(\mathrm{w} / \mathrm{v})$ bisacrylamide $(37.5: 1), 7 \mathrm{M}$ urea, $40 \mu \mathrm{l}$ $\mathrm{N}, \mathrm{N}, \mathrm{N}^{\prime}, \mathrm{N}^{\prime}$-tetramethylethylenediamine, and $0.1 \%(\mathrm{w} / \mathrm{v})$ ammonium persulfate, and were run in $1 \times$ Tris/acetate/EDTA buffer at $\mathrm{pH} 8.3$. DNA $(6 \mu \mathrm{l})$ was loaded on the gel with $6 \mu \mathrm{l}$ of in-house dye marker (50\% sucrose, $0.1 \%$ bromophenol blue) using capillary tips. The electrophoresis conditions were $46 \mathrm{~V}$ for $16 \mathrm{~h}$ with an initial temperature of $63{ }^{\circ} \mathrm{C}$ and a final temperature of $70{ }^{\circ} \mathrm{C}$ corresponding to an increase of $0.4{ }^{\circ} \mathrm{C} \mathrm{h}^{-1}$. In order to obtain thin discrete bands, a pre-migration for $15 \mathrm{~min}$ at $63{ }^{\circ} \mathrm{C}$ and $20 \mathrm{~V}$ was done after loading. Pre-migration and migration were performed with additional magnetic shaking in the electrophoresis chamber. Gels were stained for $15 \mathrm{~min}$ with $0.5 \mu \mathrm{g}$ ethidium bromide $\mathrm{ml}^{-1}$ in $1 \times$ TAE buffer, washed for $45 \mathrm{~min}$ in $1 \times$ TAE buffer, and photographed under UV illumination.

TTGE band analysis and sequencing. A specifically designed ladder was loaded on all TTGE gels corresponding to a mix of V3 region amplification products from the four isolates VA2, VA4, VA7 and VA69 (mixed TTGE pattern $1+2+5+6+7+8$ ). TTGE bands were visually detected and analysed by migration distance measuring after standardization. Each TTGE band for further analysis was cut out of the gel with a disposable sterile scalpel to avoid contamination between bands. Gel slices were washed twice in molecular biology grade water and incubated overnight at $37{ }^{\circ} \mathrm{C}$ in $10 \mathrm{mM}$ Tris buffer ( $\mathrm{pH}$ 8.5) to allow DNA diffusion. Amplification of a single 16S rRNA gene $\mathrm{V} 3$ region copy was performed using $1 \mu \mathrm{l}$ band eluate and the primers HDA1 without a GC-clamp and HDA2. The PCR was carried out in $50 \mu \mathrm{l}$ reaction mixture containing $200 \mathrm{nM}$ each primer, $200 \mu \mathrm{M}$ each dNTP, $2.5 \mathrm{mM} \mathrm{MgCl}_{2}$ and $2.5 \mathrm{U}$ Taq DNA polymerase (Go Taq; Promega) in the appropriate $1 \times$ buffer. PCR conditions were $94{ }^{\circ} \mathrm{C}$ for $2 \mathrm{~min} ; 35$ cycles of $45 \mathrm{~s}$ at $95{ }^{\circ} \mathrm{C}, 30 \mathrm{~s}$ at $62{ }^{\circ} \mathrm{C}, 1 \mathrm{~min}$ at $72{ }^{\circ} \mathrm{C}$; and $10 \mathrm{~min}$ at $72{ }^{\circ} \mathrm{C}$. PCR products were checked by electrophoresis in a $1.5 \%$ agarose gel and sequenced on an Applied Biosystems automatic sequencer (Cogenics) by using the forward 
primer HDA1. Each band was labelled by numbering for bands identified by their distance migration and by adding $\mathrm{a}, \mathrm{b}$ or $\mathrm{c}$ to the band number for co-migrating bands identified by sequencing only; the TTGE profile designation is indicated by a combination of band numbers with a + sign. The presence of different TTGE bands, i.e. $16 \mathrm{~S}$ rRNA gene $\mathrm{V} 3$ region copies with distinct sequences, in a strain or an isolate will be referred to hereafter as having intragenomic heterogeneity, while the presence of different TTGE bands in different strains or isolates will be referred to as intergenomic heterogeneity.

DNA amplification and sequencing of $r p o B$ genes. DNA (50 ng) was used as template in the PCR experiments. A $0.7 \mathrm{~kb}$ fragment of the $\beta$ subunit of the ARN polymerase $(r p o B)$ gene was amplified using primers Veill-rpoBF and Veill-rpoBR (Arif et al., 2008) for all strains and isolates except for V. montpellierensis CIP $107992^{\mathrm{T}}$ and VA50, VA100, VA110, for which primers Vmontp-rpoBF (5'-GTGTTGTATCCCGCGTTATG-3') and Vmontp-rpoBR (5'-GCACCATCAAATACAGGAGTC-3') were used. The positions of the primers on the $r p o B$ gene of $V$. parvula ATCC $10790^{\mathrm{T}}$ (GenBank accession no. EF185158) were as follows: positions 2421-2442 for Veill-rpoBF, 3100-3120 for Veill-rpoBR and Vmontp-rpoBR, and 2430-2449 for Vmontp-rpoBF. The PCR was carried out by using the same amplification conditions as previously described for 16S rRNA gene V3 regions after TTGE. The amplification profile was as follows: 35 cycles of $1 \mathrm{~min}$ at $94{ }^{\circ} \mathrm{C}, 1 \mathrm{~min}$ at $65^{\circ} \mathrm{C}, 2 \mathrm{~min}$ at $72{ }^{\circ} \mathrm{C}$; and a final extension of $10 \mathrm{~min}$ at $72{ }^{\circ} \mathrm{C} . r p o B$ gene PCR products were sequenced on an Applied Biosystems automatic sequencer (Cogenics) by using forward or reverse primer.

Sequence analysis and tree construction. DNA sequences were visualized and analysed with BioEdit programme version 7.0.9 (Hall, 1999). RNA secondary structure by energy minimization was predicted using the Mfold programme version 3.4 (http://mfold. bioinfo.rpi.edu/) (Zuker, 2003). Before phylogenetic analysis, the $r p o B$ sequences were aligned with CLUSTAL_X (Thompson et al., 1997) and alignments were manually checked and corrected. Clostridium perfringens rpoB sequence (AB055810) was used as an outgroup. Distance-based phylogeny was computed using the PHYLIP package (Felsenstein, 1997) with F84 as a substitution model in the DNADIST program and neighbour-joining method (NEIGHBOR program). A total of 1000 bootstrapped trees were sampled to test the robustness of the nodes and a consensus tree was reconstructed with CONSENSE program. The maximum-likelihood (ML) tree was constructed using PhyML programs (Guindon \& Gascuel, 2003) with GTR + invariant sites + gamma-distribution. For the ML tree, bootstraps were determined by 100 reiterations. A distance matrix in nexus format was generated from $r p o B$ clade types and from the presence or absence of each of the 43 TTGE bands in the TTGE profiles, and then used for decomposition analysis with SplitsTree 4.0 software (Huson \& Bryant, 2006).

\section{RESULTS}

\section{PCR-TTGE patterns reflect the diversity of the V3 region among the Veillonella population}

PCR-TTGE analysis generated interpretable patterns for the 149 clinical isolates and the 13 type or reference strains (Fig. 1). A total of 307 TTGE bands were observed. Among them, $201(65.5 \%)$ bands were selected for sequencing as follows: (i) 36 bands with different migration distances; (ii) 1-12 bands for each of the 36 migration distances; and (iii) one of each band of the 54 TTGE pattern types. This sequencing strategy confirmed that the sequence of the $16 \mathrm{~S}$ rDNA V3 region differed according to the migration distance. Conversely, in most cases, bands with identical migration distance displayed the same sequence except for 7 bands found in 11 isolates that showed very close migration distances and variable sequences $(7.4 \%$ of the bands) (Table 1).

Some extra fragments generated during PCR or TTGE should be noted and excluded from pattern analysis in order to avoid any overestimation of band number (Satokari et al., 2001). As previously described, some artefacts may be generated during PCR by reassociation of DNA strands with slightly different sequences. Heteroduplex bands are recognized by their low intensity associated with reduced migration distances when compared with homoduplex bands, owing to their lower melting temperatures. Between one and five heteroduplex bands were observed within a TTGE pattern composed of multiple bands (Fig. 1); these bands were confirmed as heteroduplexes by a novel run of 16S rDNA PCR-TTGE showing an identical double band profile. Identical

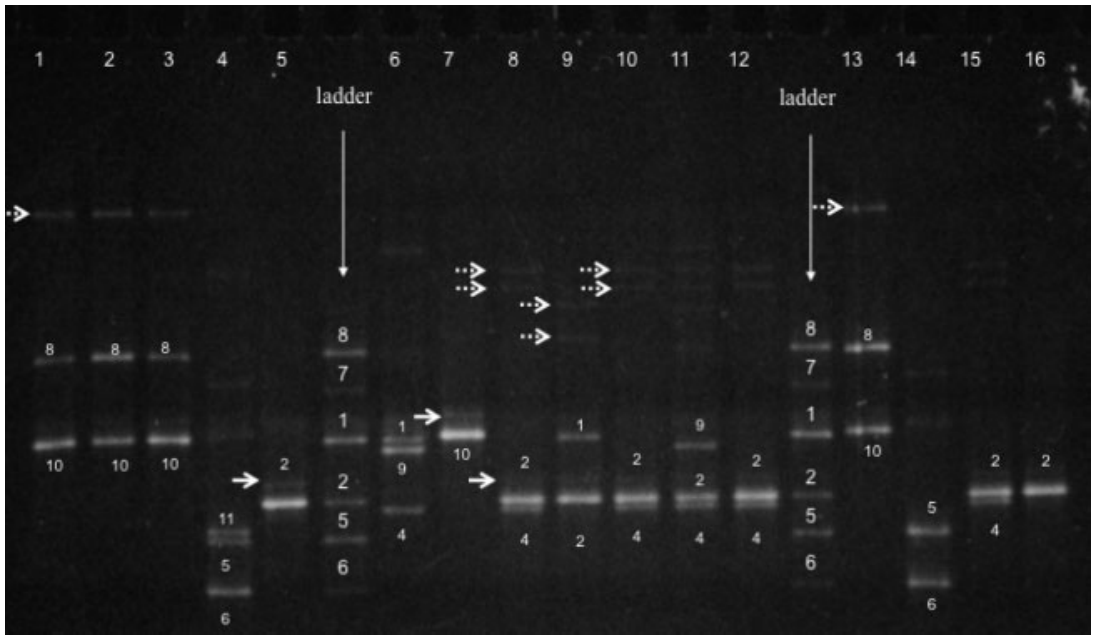

Fig. 1. TGGE profiles of amplified V3 $16 \mathrm{~S}$ rDNA for 16 Veillonella spp. clinical isolates. Lanes: 1-16, isolates VA74, VA83-85 and VA87-98, respectively; ladder, mix of four isolates with profiles $1+2,1+7,5+6$ and 8 . Each band number is noted on the band. Dotted arrows indicate heteroduplexes. Solid arrows indicate bands with delayed migration, which had identical sequences to the homoduplex band below. 
heteroduplex bands were observed for all the strains or isolates displaying a specific TTGE pattern. We also observed bands of low intensity migrating slightly above the homoduplex bands (Fig. 1). As previously observed by Janse et al. (2004), sequencing showed that these bands with delayed migration had identical sequences to the homoduplex band below and were not further considered during pattern analysis. Hereafter, 'TTGE band' will refer to non-artefactual bands excluding heteroduplex and delayed bands.

A very large diversity of TTGE patterns was noted among the 162 strains and isolates, as 54 distinct profiles were observed; 45 among the clinical isolates and 13 for the 13 type or reference strains. Only four TTGE patterns were common to clinical isolates and type strains: $V$. rogosae DSM $18960^{\mathrm{T}}$ and 13 clinical isolates shared the same profile, and $V$. dispar ATCC $17748^{\mathrm{T}}$, V. atypica ATCC $17744^{\mathrm{T}}$ and $V$. parvula ATCC $10790^{\mathrm{T}}$ displayed identical profiles to those of seven, three and two clinical isolates, respectively. Thus, diversity observed from TTGE patterns in the studied population was higher than expected from the diversity of the known species in the genus. Forming the 54 patterns, 43 TTGE bands differing by their migration distance and/or sequence were identified (Table 1). Sequencing detected a total of 30 variable positions localized from position 415 to position 492 . These variable positions were located in the helices H16 and H17 of the rRNA molecule (Case et al., 2007) corresponding to helices H406 (position 406-436, E. coli numbering) and $\mathrm{H} 441$ (position 441-493, E. coli numbering) according to the nomenclature of the Gutell Lab database (http://www.rna.ccbb.utexas.edu/). Six of the 30 variable positions accounted for intergenomic diversity only, six were variable at the intragenomic level only and 18 were variable at both intragenomic and intergenomic levels (Table 1). Sequencing and 2D reconstruction of the mostly complete H17 rRNA helix revealed 10 different secondary structure types for the 43 different sequences (Supplementary Fig. S1, available with the online version of this paper).

\section{Intragenomic heterogeneity among Veillonella spp.}

Intragenomic heterogeneity among rrs copies was revealed by TTGE profiles with multiple bands further called 'heterogeneous profiles'. Heterogeneous profiles were shown for 110 of the 149 isolates $(74 \%$ of the isolates, 37 profiles). They displayed two (84 isolates, $56 \%$ ) or three bands (26 isolates, $18 \%$ ). Five main heterogeneous profiles were observed, $1+2(n=19), 2+4(n=19), 8+10(n=13)$, $5+6(n=11)$ and $5+6+11(n=5)$, including $60.9 \%$ of the clinical isolates. Heterogeneous profiles were observed for $61.5 \%$ of type and reference strains (8 of 13 strains), with each strain displaying a specific profile (Tables 2 and 3 ). Sequencing showed that within a genome, between 1 and 5 positions of the V3 region $(0.5 \%$ to $2.5 \%)$ were divergent between $16 \mathrm{~S}$ rDNA copies. However, in $75 \%$ of the heterogeneous TTGE profiles, no more than two hetero- geneous positions (1\%) were detected. Intragenomic heterogeneity was mainly associated with transitions CT or AG (23 cases) or more rarely with a GT transversion (two cases). The polymorphic position 458 was the only variable nucleotide position characterized either by transition CT (TTGE patterns $1+7,1+10,8+10$ and $7 \mathrm{~b}+8+10$ ) or by transversion (profiles $1 \mathrm{a}+34$ and $1 a+5 a+34)$. The majority of these positions are localized in the helix H17 between nt 444 and 492 (E. coli numbering) (Table 1), resulting in 10 different secondary structure types for the 43 TTGE bands (Supplementary Fig. S1). In 15 of the 44 heterogeneous profiles (34.1\%), intragenomic heterogeneity resulted in 16S rRNA gene copies with different secondary structure to the H17 helix. The impact of heterogeneous positions on the secondary structure was independent of their number. For example, two heterogeneous positions may change the secondary structure of the stem-loop (TTGE profile $5+13$ ), while five heterogeneous positions did not change this structure due to compensating base co-variation in the stem-loop region (TTGE profile 7+1). Different secondary structure types were more frequently observed in strains and isolates with three different copies ( 9 of 15 heterogeneous profiles, $60 \%)$ than in strains and isolates with two different copies (6 of 29 heterogeneous profiles, $20.7 \%$ ). The TTGE pattern $1+9 a+2$, observed for the clinical isolate VA79, was the only one displaying three secondary structure types (structures 1, 2 and 3).

\section{Structure of the bacterial population on the basis of rpoB gene phylogeny}

Distance and ML rpoB-based phylogenetic trees were congruent (an ML rpoB-based tree is shown in Supplementary Fig. S2). The population of clinical isolates was distributed in eight clades. Six of the eight clades included type strains of species of the genus Veillonella; clade 1 included $V$. parvula, clade $2 V$. rogosae, clade $3 V$. dispar, clade $5 \mathrm{~V}$. atypica, clade $6 \mathrm{~V}$. montpellierensis and clade $7 \mathrm{~V}$. ratti (Supplementary Fig. S2). The polyphyletic clade 1 was considered as a taxonomically unique clade, since both subbranches supported a reference strain of $V$. parvula. Phylogenetic analysis indicated the presence of two other clades (clades 4 and 8 ) that did not contain a type strain of a known species. $V$. denticariosi, $V$. rodentium, $V$. caviae, $V$. criceti and $V$. magna type and reference strains did not group with clinical isolates. $V$. denticariosi and $V$. rodentium formed an additional clade. Distribution of clinical isolates in the eight rpoB-based clades is given in Table 2. It is noteworthy that $16 \mathrm{~S}$ rRNA gene intragenomic heterogeneity was observed in all rpoB-based clades - ranging from $20 \%$ of clinical isolates belonging to $V$. dispar clade 3 to $100 \%$ of clinical isolates belonging to $V$. ratti clade 7 - and in $V$. denticariosi, V. caviae and V. criceti strains (Tables 2 and 3 ).

For further analysis, we considered that rpoB clades 1 to 8 were each representative of a known or unknown Veillonella species, and comparisons at both intra- and 
Table 1. Sequence differences among the 43 TTGE bands observed in the Veillonella population, $r r s$ V3 region secondary structures, TTGE patterns and $r p o B$-based clades Nucleotide positions compared with those in band 1 are indicated by their variant nucleotide when divergent or by "--" when identical. For divergent positions, bold type indicates intergenomic heterogeneity, italic type indicates an intragenomic transition CT or AG, and Roman type (no bold or italic) indicates an intragenomic transversion GT.

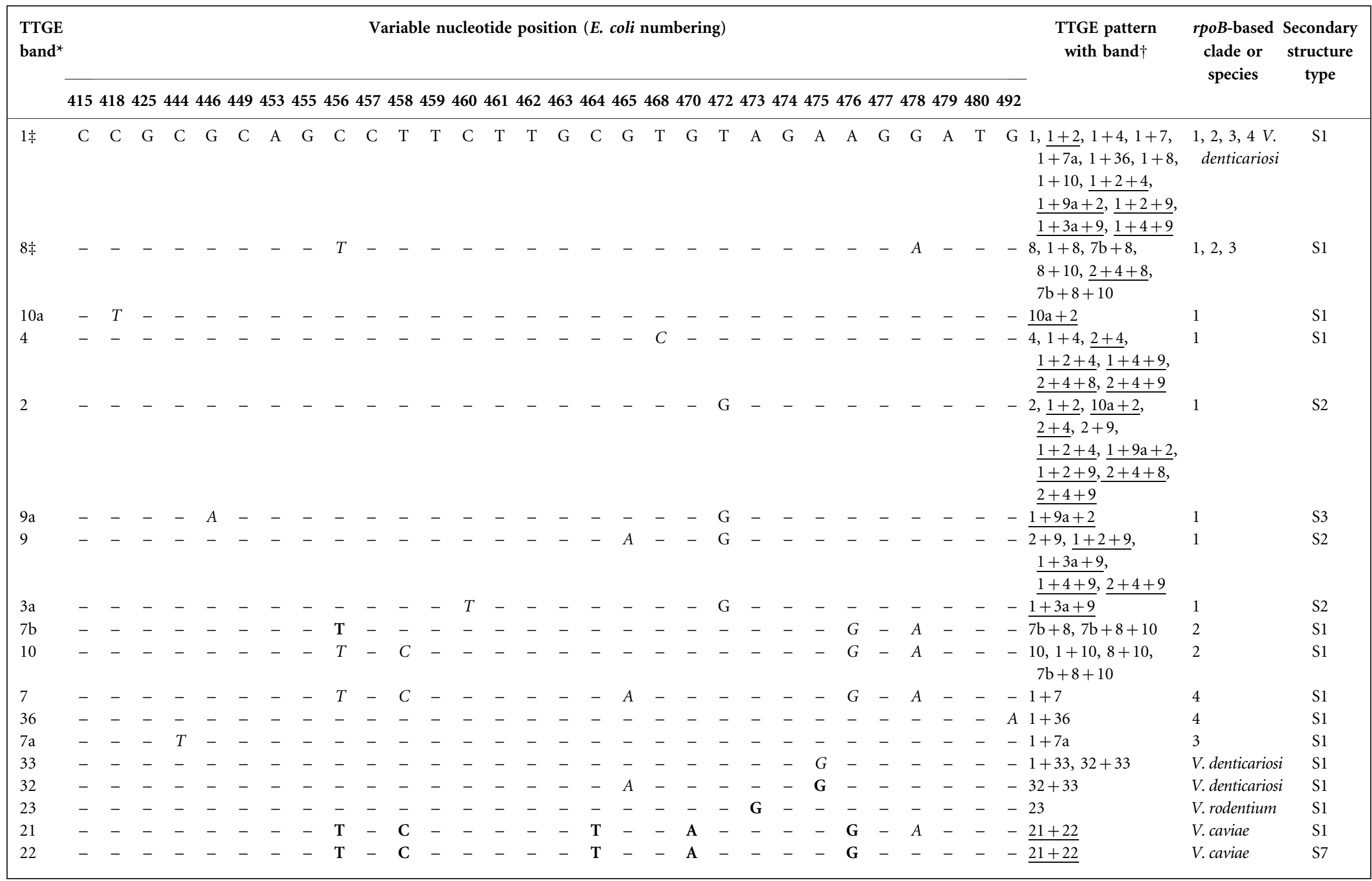


Table 1. cont.

\begin{tabular}{|c|c|c|c|c|c|c|c|c|c|c|c|c|c|c|c|c|c|c|c|c|c|c|c|c|c|c|c|c|c|c|c|c|}
\hline \multirow{2}{*}{$\begin{array}{l}\text { TTGE } \\
\text { band }^{*}\end{array}$} & \multicolumn{29}{|c|}{ Variable nucleotide position (E. coli numbering) } & \multirow{2}{*}{$\begin{array}{l}\text { TTGE pattern } \\
\text { with band } \dagger\end{array}$} & \multirow{2}{*}{$\begin{array}{c}\text { rpob-based } \\
\text { clade or } \\
\text { species }\end{array}$} & \multirow{2}{*}{$\begin{array}{c}\text { Secondary } \\
\text { structure } \\
\text { type }\end{array}$} \\
\hline & 415 & 418 & 425 & 444 & 146 & 449 & 453 & 155 & 456 & 157 & 158 & 459 & 460 & 461 & 462 & 463 & 464 & 465 & 468 & 470 & 472 & & 474 & 475 & 476 & 477 & 478 & 4794 & 480 & & & \\
\hline 3 & - & - & - & - & - & - & $\mathrm{T}$ & - & $\mathrm{T}$ & $\mathrm{T}$ & $\mathrm{C}$ & - & $\mathrm{T}$ & G & - & - & - & $A$ & - & - & G & $\mathrm{C}$ & A & - & G & - & A & $\mathrm{T}$ & - & $-3+5,3+5+6$ & 5 & S4 \\
\hline 11 & - & - & - & - & - & - & $\mathrm{T}$ & - & $\mathrm{T}$ & $\mathrm{T}$ & $\mathrm{C}$ & - & $\mathrm{T}$ & G & - & - & - & - & - & - & G & $\mathrm{C}$ & $A$ & - & G & - & A & $\mathrm{T}$ & - & $-5+6+11$ & 5 & S4 \\
\hline 12 & - & - & - & - & - & - & $\mathrm{T}$ & - & $\mathrm{T}$ & $T$ & $\mathrm{C}$ & - & $\mathrm{T}$ & G & - & - & - & - & - & - & G & $\mathrm{C}$ & - & - & G & $A$ & A & $\mathrm{T}$ & - & $-5+6+12$ & 5 & S4 \\
\hline 13 & - & - & - & - & - & - & $\mathrm{T}$ & - & $\mathrm{T}$ & $\mathrm{T}$ & $\mathrm{C}$ & - & $\mathrm{T}$ & G & - & $A$ & - & $A$ & - & - & G & $\mathrm{C}$ & - & - & G & $A$ & A & $\mathrm{T}$ & - & $-\underline{5+13}$ & 5 & S10 \\
\hline 14 & - & - & - & - & - & - & $\mathrm{T}$ & - & $\mathrm{T}$ & $\mathrm{T}$ & $\mathrm{C}$ & - & $\mathrm{T}$ & G & - & - & $T$ & - & - & - & G & $\mathrm{C}$ & - & - & G & - & A & $\mathrm{T}$ & - & $-\overline{6+14}, 5+6+14$ & 5 & S4 \\
\hline 19 & - & - & - & - & - & - & $\mathrm{T}$ & - & $\mathrm{T}$ & - & - & - & $\mathrm{T}$ & G & - & - & - & - & - & - & G & $\mathrm{C}$ & A & - & G & - & A & $\mathrm{T}$ & - & $-19+20$ & 7 & S4 \\
\hline 20 & - & - & - & - & - & - & $\mathrm{T}$ & - & $\mathrm{T}$ & - & - & - & $\mathrm{T}$ & G & - & - & - & - & - & - & G & $\mathrm{C}$ & $\mathbf{A}$ & G & - & - & A & $\mathrm{T}$ & - & $-19+20$ & 7 & S4 \\
\hline 34 & - & $\mathrm{T}$ & A & - & - & - & $\mathrm{T}$ & - & $\mathrm{T}$ & - & G & G & $\mathrm{T}$ & G & - & - & - & A & - & - & G & $\mathrm{C}$ & A & $\mathrm{T}$ & G & - & A & $\mathrm{C}$ & A & $=34, \frac{1 a+34}{1 a+5 a+34}$ & 6 & S6 \\
\hline $5 a$ & - & $\mathrm{T}$ & A & - & - & - & $\mathrm{T}$ & - & $\mathrm{T}$ & - & - & G & $\mathrm{T}$ & G & - & - & - & A & - & - & G & $\mathrm{C}$ & $\mathbf{A}$ & $\mathrm{T}$ & - & - & A & $\mathrm{C}$ & A & $-1 \overline{a+5 a+34}$ & 6 & S5 \\
\hline $1 \mathrm{a}$ & - & $\mathrm{T}$ & A & - & - & - & $\mathrm{T}$ & - & $\mathrm{T}$ & $T$ & - & G & $\mathrm{T}$ & G & - & - & - & A & - & - & G & $\mathrm{C}$ & $\mathbf{A}$ & $\mathrm{T}$ & - & - & A & $\mathrm{C}$ & A & $-\overline{1 a+5 a+34}$ & 6 & S5 \\
\hline 31 & - & - & - & - & - & - & - & A & G & - & $\mathrm{C}$ & - & $\mathrm{T}$ & G & - & - & $\mathrm{T}$ & - & - & A & G & $\mathrm{C}$ & - & - & G & - & A & - & G & $-\overline{31}$ & V. magna & S8 \\
\hline 24 & $\mathbf{A}$ & $\mathrm{T}$ & A & - & - & - & - & A & G & $\mathrm{T}$ & - & C & $\mathrm{T}$ & G & - & - & $\mathrm{T}$ & $A$ & - & $\mathbf{A}$ & G & $\mathrm{C}$ & $\mathbf{A}$ & G & - & $\mathbf{A}$ & $\mathbf{A}$ & - & G & $\begin{array}{c}-24+25,24+26 \\
24+28\end{array}$ & 8 & S8 \\
\hline 25 & $\mathbf{A}$ & $\mathrm{T}$ & A & - & - & - & - & A & G & $\mathrm{T}$ & - & C & $\mathrm{T}$ & G & - & - & $\mathbf{T}$ & - & - & $\mathbf{A}$ & G & $\mathrm{C}$ & $\mathbf{A}$ & G & - & $\mathbf{A}$ & $\mathbf{A}$ & - & $\mathbf{G}$ & $\begin{array}{c}-25,24+25 \\
25+26+27\end{array}$ & 8 & S8 \\
\hline 26 & A & $\mathrm{T}$ & A & - & - & - & - & A & G & $\mathrm{T}$ & - & $\mathrm{C}$ & $\mathrm{T}$ & G & C & - & $\mathrm{T}$ & - & - & A & G & $\mathrm{C}$ & A & G & - & A & A & - & G & $-24+26, \underline{25+26+27}$ & 8 & S8 \\
\hline 27 & A & $\mathrm{T}$ & A & - & A & - & - & A & G & $\mathrm{T}$ & - & $\mathrm{C}$ & $\mathrm{T}$ & G & - & - & $\mathrm{T}$ & $A$ & - & A & G & $\mathrm{C}$ & A & G & - & A & A & - & G & $-25+26+27$ & 8 & S9 \\
\hline 28 & A & $\mathrm{T}$ & A & - & - & - & - & A & G & $\mathrm{T}$ & - & $\mathrm{C}$ & $\mathrm{T}$ & G & - & - & $\mathrm{T}$ & $A$ & - & A & G & $\mathrm{C}$ & A & G & G & A & A & - & G & $-24+28$ & 8 & S8 \\
\hline 29 & $\mathbf{A}$ & $\mathrm{T}$ & A & - & - & $T$ & - & A & G & $\mathrm{T}$ & - & $\mathrm{C}$ & $\mathrm{T}$ & G & - & - & $\mathrm{T}$ & - & - & A & G & $\mathrm{C}$ & $\mathbf{A}$ & G & - & $\mathbf{A}$ & A & - & G & $-29+30$ & 8 & S8 \\
\hline
\end{tabular}

${ }^{\star}$ TTGE bands differing by their migration distance are numbered; bands identified by sequencing only are indicated by a and $b$.

†TTGE patterns, including bands with different secondary structures are underlined.

¥Bands were found in TTGE patterns from isolates belonging to several rpoB-based clades or several Veillonella species. 
Table 2. V3 $16 \mathrm{~S}$ rDNA PCR-TTGE results for isolates and strains of Veillonella spp. of the eight rpoB-based clades

Bands not present in the TTGE patterns of strains and isolates belonging to different $r p o B$-based clades are in bold type; bands shared by the TTGE patterns of strains or isolates belonging to different $r p o B$-based clades are underlined.

\begin{tabular}{|c|c|c|c|c|c|c|}
\hline $\begin{array}{l}\text { rpoB-based clade } \\
\text { (no. of isolates, \% ) }\end{array}$ & $\begin{array}{l}\text { Clade's type and } \\
\text { reference strain } \\
\text { (TTGE pattern) }\end{array}$ & $\begin{array}{c}\text { Isolates with } \\
\text { TTGE } \\
\text { heterogeneity } \\
\text { profile no. (\%) }\end{array}$ & $\begin{array}{c}\text { Intragenomic } \\
\text { variable position } \\
\text { no. ( } \% \text { of isolates) }\end{array}$ & $\begin{array}{l}\text { Main TTGE } \\
\text { bands }(\%)^{*}\end{array}$ & $\begin{array}{c}\text { Main TTGE } \\
\text { patterns }(\%)^{*}\end{array}$ & $\begin{array}{l}\text { Other TTGE } \\
\text { bands }(\%)^{*}\end{array}$ \\
\hline Clade $1(72,48.3)$ & $\begin{array}{l}\text { V. parvula ATCC } 10790^{\mathrm{T}} \\
(4) ; \text { V. parvula CIP } 60.1 \\
(1+4)\end{array}$ & $50(69.4)$ & $\begin{array}{c}0(30.6) ; 1(29.2) ; \\
2(33.3) ; 3(5.5) ; \\
4(1.4)\end{array}$ & $\begin{array}{l}2(94.4) ; \\
4(37.5) ; \\
1 \quad(34.7)\end{array}$ & $\begin{array}{l}2(27.7) \\
1+2(26.4) \\
2+4(26.4)\end{array}$ & $\begin{array}{c}9(9.7) ; 10 a, 9 a, 3 a, \\
\underline{8}(1.4 \text { each })\end{array}$ \\
\hline Clade $2(21,14.1)$ & $\begin{array}{l}\text { V. rogosae DSM } 18960^{\mathrm{T}} \\
(8+10)\end{array}$ & $18(85.7)$ & $\begin{array}{l}0(14.3) ; 1(4.75) ; \\
2(76.2) ; 4(4.75)\end{array}$ & $\begin{array}{r}10 \\
\quad(90.5) ; \\
\underline{8}(85.7)\end{array}$ & $8+10(61.9)$ & $7 \mathbf{b}(19) ; \underline{1}(5)$ \\
\hline Clade $3(10,6.7)$ & $\begin{array}{l}\text { V. dispar ATCC } \\
17748^{\mathrm{T}}(1)\end{array}$ & $2(20)$ & $0(80) ; 1(10) ; 2(10)$ & $\underline{1}(90)$ & $1(70)$ & $\underline{8}(20) ; 7 \mathbf{a}(10)$ \\
\hline Clade $4(2,1.4)$ & - & $2(100)$ & $1(50) ; 5(50)$ & $\underline{1}(100)$ & $\begin{array}{l}7+1(50) \\
36+1(50)\end{array}$ & 7, 36 (50 each) \\
\hline Clade $5(30,20.1)$ & $\begin{array}{l}\text { V. atypica ATCC } 17744^{\mathrm{T}} \\
\text { (6) }\end{array}$ & $27(90)$ & $0(10) ; 1(50) ; 2(40)$ & $\begin{array}{l}\mathbf{6}(93.3) ; \\
\mathbf{5}(83.3)\end{array}$ & $5+6(36.6)$ & $\begin{array}{r}11(16.7) ; 3(13.3) ; \\
14(10) ; 12(6.7) ; \\
35(3.3) ; 13(3.3)\end{array}$ \\
\hline Clade $6(3,2)$ & $\begin{array}{l}V . \text { montpellierensis CIP } \\
107992^{\mathrm{T}}(1 \mathrm{a}+5 \mathrm{a}+34)\end{array}$ & $2(66.7)$ & $0(33.3) ; 3(66.7)$ & $\begin{array}{l}34(100) \text {; } \\
\text { 1a }(66.7)\end{array}$ & $1 \mathrm{a}+34(66.7)$ & - \\
\hline Clade $7(4,2.7)$ & $\begin{array}{l}\text { V. ratti ATCC } 17746^{\mathrm{T}} \\
(17+18)\end{array}$ & $4(100)$ & $1(25) ; 2(25) ; 3(50)$ & $\begin{array}{c}17(100) ; \\
15(75) ; 16(75)\end{array}$ & $15+16+17(50)$ & - \\
\hline Clade $8(7,4.7)$ & - & $5(71.4)$ & $\begin{array}{l}0(28.6) ; 1(28.6) ; \\
2(14.2) ; 3(28.6)\end{array}$ & $\begin{array}{l}25(57.1) ; \\
24(42.9)\end{array}$ & $25(28.6)$ & $\begin{array}{l}26(28.6) ; 27,28, \\
29,30(14.3 \text { each })\end{array}$ \\
\hline
\end{tabular}

${ }^{\star}$ TTGE bands and TTGE patterns are described in Methods.

interclade levels were referred to as comparisons at intraand interspecific levels, respectively.

\section{Comparative analysis of $r p o B$-based bacterial population structure and TTGE band patterns}

Inter- and intraspecific V3 heterogeneities were analysed with respect to $r p o B$ population structure. To this end, we used a decomposition analysis based on the $r p o B$ clade and TTGE banding profiles. Congruence between rpoB-based clade/species type and rrs $\mathrm{V} 3$ region type would lead to a radial structure of the graph. Dissociation between $r p o B$ based clade/species type and rrs V3 region type suggestive of recombination events would lead to a network-like graph. On the split tree (Fig. 2), two groups of strains and isolates were observed. Strains and isolates belonging to clades 5-8 together with $V$. rodentium, $V$. caviae, $V$. criceti and $V$. magna type strains formed the first group, known hereafter as group A. They were organized in radial branches without network-like links among branches supporting clades and species. Network-like links were observed inside each clade. The split tree suggested that

Table 3. V3 $16 \mathrm{~S}$ rDNA PCR-TTGE results of species for which type and reference strains did not group with clinical isolates in the $r p o B$-based phylogenetic tree

\begin{tabular}{|llcc|}
\hline Species & Type or reference strain & TTGE profile $^{*}$ & $\begin{array}{c}\text { No. of intragenomic } \\
\text { variable positions }\end{array}$ \\
\hline V. denticariosi & V. denticariosi CIP $109448^{\mathrm{T}}$ & $32+33$ & 1 \\
V. rodentium & V. denticariosi CIP 109449 & $1+33$ & 1 \\
V. caviae & V. rodentium ATCC $17743^{\mathrm{T}}$ & 23 & 0 \\
V. criceti & V. caviae DSM $20738^{\mathrm{T}}$ & $21+22$ & 2 \\
V. magna & V. criceti DSM $20734^{\mathrm{T}}$ & $19+20$ & 0 \\
\hline
\end{tabular}

^TTGE profiles are described in Methods; TTGE band shared by TTGE patterns of strains or isolates belonging to different $r p o B$-based clades in Table 2 are underlined. 


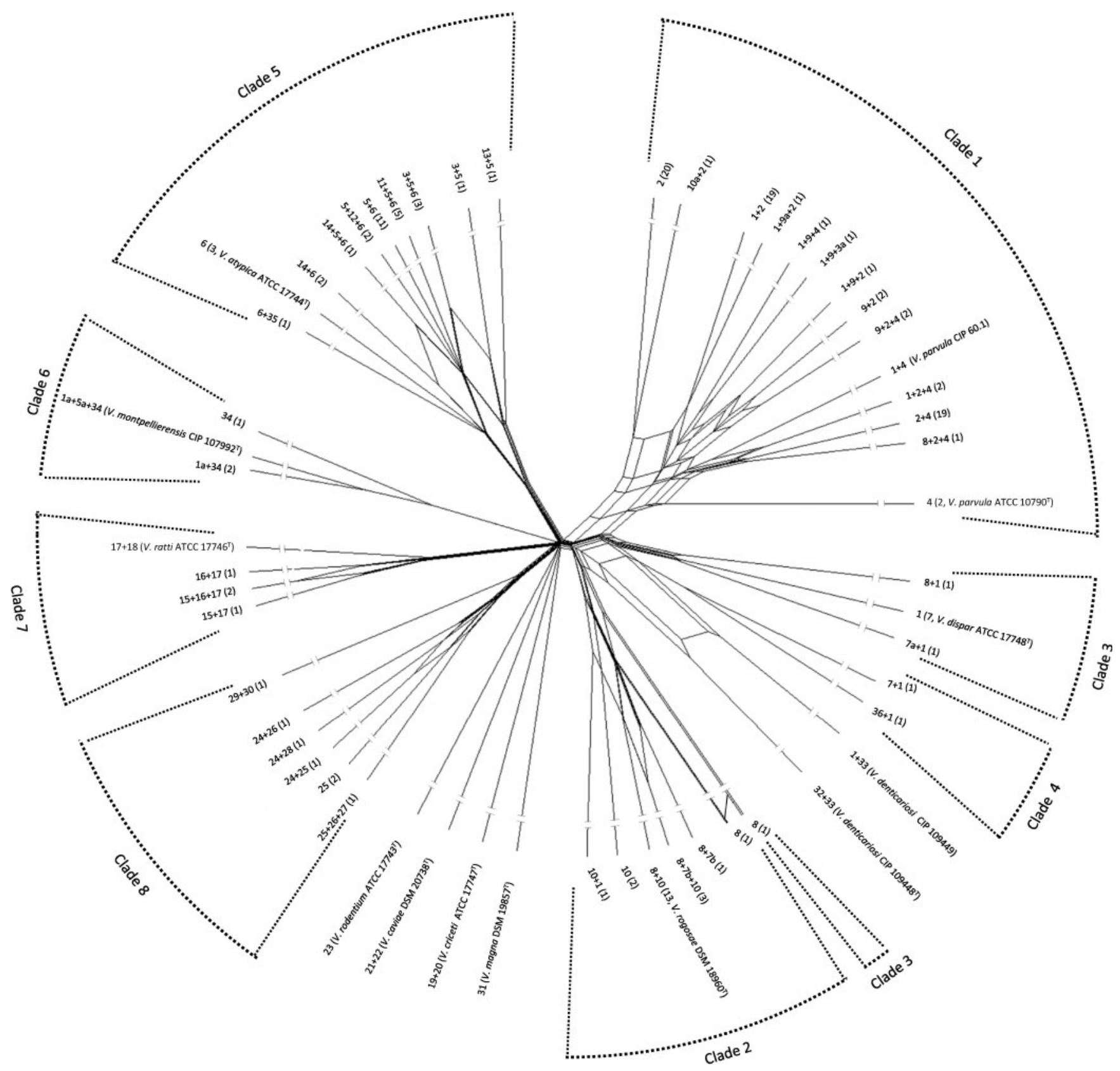

Fig. 2. SplitsTree decomposition analyses of PCR-TTGE and rpoB-based clustering data for clinical isolates and type and reference strains of the genus Veillonella. PCR-TTGE patterns are indicated the extremity of each tree branch with the number of clinical isolates and/or name of reference or type strain displaying the corresponding pattern indicated in parentheses. rpo $B$-based clades of clinical isolates are indicated by the clade's number and are delimited by dotted lines.

recombination events occurred inside clades but each clade and species appeared genetically isolated from each other. TTGE bands were clade-specific in this group (Tables 2 and 3 ). High V3 region polymorphism (6-17 different nucleotides) was noted between group A members; in particular interspecific V3 polymorphism was always greater than intraspecific and intragenomic V3 heterogeneity among each of clades 5, 6, 7 and 8 .
Strains and isolates belonging to clades $1-4$ and to $V$. denticariosi formed a second group named group B. A network-like structure was observed on the split tree among group B strains (Fig. 2). Genetic recombination was observed inside each clade and also between strains and isolates belonging to different clades/species. Some TTGE bands were shared among clades of group B, such as band 1 among clades 1-4 and band 8 among clades 1-3 (Table 2). 
For example, a copy of the $\mathrm{V} 3$ region observed in $90 \%$ of $V$. dispar group isolates was present in $34.7 \%$ of the $V$. parvula group isolates, and was also observed in the reference strain $V$. denticariosi CIP 109449. Similarly, a V3 region copy found in $85 \%$ of members of the $V$. rogosae clade was identical to a V3 region copy found in $20 \%$ of $V$. dispar group isolates. These observations suggested that horizontal gene transfer of $r r n$ might occur between these species. At the interspecific level, a low polymorphism (1-6 divergent positions) was observed among clades and species of group B (data not shown). In these cases, intragenomic microheterogeneity and intraspecific rrs polymorphism levels may be higher than interspecific polymorphism. Finally, high V3 region polymorphism was noted between groups $\mathrm{A}$ and $\mathrm{B}$ and recombination did not occur between these two groups. We compared the tree in Fig. 2 with a split tree constructed on the basis of $r p o B$ clade/species type, $r r s \mathrm{~V} 3$ region type and 2D structure type of the $\mathrm{V} 3$ region (D2V3) (data not shown). On the basis of this comparison and of data in Table 1, D2V3 appeared to be shared inside clades, particularly in clades 5 and 8 , independently of the V3 region sequence type. D2V3 was also shared between clades/species that did not experience V3 exchanges or recombination. This was particularly notable between clade 5 and $V$. criceti, between clade 8 and $V$. magna, between $V$. rodentium and group B representatives, and finally between clade 1 and $V$. caviae (Table 1 ). This suggested that the same secondary structure based on different sequences could appear independent from genetic exchanges in different lineages.

\section{DISCUSSION}

Intragenomic heterogeneity between $16 \mathrm{~S}$ rRNA gene copies has been described for a range of bacteria. Therefore, evaluating the extent of these heterogeneities in natural populations is essential for determining how they impair the results of $16 \mathrm{~S}$ rDNA-based identification, taxonomy and metagenomics (Dahllöf et al., 2000). Operon heterogeneity may be detected by sequencing chromatogram examination revealing double peaks or by unexpected RFLP patterns of amplified rDNA but it could not be further investigated using these approaches (Marchandin et al., 2003). Visualization of heteroduplexes after $16 \mathrm{~S}$ rDNA PCR amplification and PAGE was also reported to be indicative of intragenomic polymorphism; it is suitable for easy testing of large numbers of strains but a cloning step remains necessary for a precise study of microheterogeneity (Moreno et al., 2002). Cloning experiments involving sequencing of numerous clones for each isolate, complete genome sequencing and PFGE (Marchandin et al., 2003) allowed the study of a limited number of strains and are not appropriate for population studies (Marchandin et al., 2003; Conville \& Witebsky, 2007). PCR-TTGE is based on electrophoretic separation of amplicons with the same length but different sequences by using a temperature gradient to denature the DNA. It was previously optimized to reveal differences in the $16 \mathrm{~S}$ rDNA V3 regions of bacteria (Roudière et al., 2009), each sequence variation producing a distinctive band migration distance. PCR-TTGE was previously demonstrated to be suitable for detection of divergence in 16S rRNA genes in four Paenibacillus polymyxa strains (Nübel et al., 1996) but has remained very rarely applied to bacterial populations since the study by Nübel and colleagues.

We used PCR-TTGE to describe 16S rRNA gene intragenomic, intraspecific and interspecific diversity in a natural population of clinical isolates of Veillonella species. We showed that PCR-TTGE was an accurate, sensitive, powerful and rapid method for revealing rrs sequence heterogeneities in a large population. Exhaustive detection of the different $r r s$ sequences represented in the population is easier than using cloning experiments, which require analysis of a statistically significant number of clones to determine the number of different rrs copies. The combined approach associating comparisons of band migration distances with a specifically designed ladder and sequencing from selected excised bands made this method inexpensive compared with other methods.

High occurrence $(74 \%)$ of intragenomic heterogeneity was demonstrated for the 149 studied clinical isolates, which is in accordance with previous PCR-RFLP-based results (Marchandin et al., 2003). Although the H17 helix constituted one of the more variable rrs regions in the genus Veillonella (Marchandin et al., 2003) and in 111 genomes studied by Case et al. (2007), intragenomic microheterogeneity may concern an even higher rate of isolates if the complete gene was studied (Coenye \& Vandamme, 2003). Analysis of sequencing patterns for 475 representatives of the genus Streptomyces and RFLP-based analysis conducted on 82 Aeromonas strains revealed the presence of different rrs copies in 21 and $6.9 \%$ of strains, respectively (Ueda et al., 1999; Graf, 1999). Moreno et al. (2002) studied four type strains and 20 environmental isolates of Vibrio spp. by PCR-PAGE, which revealed $16 \mathrm{~S}$ rDNA polymorphism for all strains. Thus, the genus Veillonella displayed one of the highest occurrences of $16 \mathrm{~S}$ rRNA gene intragenomic heterogeneity described so far.

Among the two types of operon heterogeneity currently described in bacterial genomes, i.e. microheterogeneity and macroheterogeneity (Teyssier et al., 2003), microheterogeneity mostly accounted for $16 \mathrm{~S}$ rRNA molecule heterogeneity (Acinas et al., 2004), as previously reported for Veillonella sp. strain ADV360.1 (Marchandin et al., 2003) and several other taxa (Cilia et al., 1996; Martínez-Murcia et al., 1999; Ninet et al., 1996; Nübel et al., 1996; Yap et al., 1999). Acinas et al. (2004) noted divergence between rrs copies in $62 \%$ of the 76 bacterial genomes, which possessed at least two copies of $16 \mathrm{~S}$ rDNA. Four $\mathrm{rrn}$ operons were present in strains of the genus Veillonella analysed so far (Marchandin et al., 2003; data not shown). Heterogeneity occurred at between 0 and 5 positions $(0-$ $2.5 \%$ ) of the variable region $\mathrm{V} 3$ and the average percentage 
of nucleotide divergence was $0.89 \%$. Although we did not review here the 87 sequenced genomes containing four $\mathrm{rrn}$ operons currently referenced in $\mathrm{rrnDB}$ (http://ribosome. $\mathrm{mmg} . \mathrm{msu} . e d u / \mathrm{rrndb} /)$, this value seemed particularly high when compared with results previously published for most genomes with four rrs copies (Coenye \& Vandamme, 2003; Acinas et al., 2004). Except for Thermobispora bispora and Thermoanaerobacter tengcongensis, which display 6.4 and $6.5 \%$ rrs microheterogeneity, respectively, the 11 other examined genomes showed a mean divergence of $0.025 \%$ between copies (range, $0-0.07 \%$ ). Among variable positions, transitions were the dominant type of mutation, as previously reported (Coenye \& Vandamme, 2003), suggesting that divergence of $r r s$ copies may occur by mutation after gene duplication (Yap et al., 1999). Transversions were observed for 48 isolates belonging to $V$. parvula clade 1 and for the three representatives of $V$. montpellierensis clade 6 . In some cases, substitutions change the secondary structure of helix $\mathrm{H} 17$ and may thus impact ribosomal function, since $\mathrm{H} 17$ plays a major role in the first steps of the 3D folding (Adilakshmi et al., 2005). At the interspecies level, the same secondary structures were observed among different clades. These common secondary structures derived from different sequences indicated they were not the result of recombination events but rather suggested convergent evolution of some rrs.

Among the housekeeping genes previously studied in the genus Veillonella, dnaK, gyrB and $r p o B$ were demonstrated as more discriminatory between species than 16S rRNA gene, with $r p o B$ being the most discriminatory. Indeed, several species, such as $V$. parvula and $V$. dispar (Marchandin et al., 2003), V. denticariosi and V. rodentium (Byun et al., 2007), or V. ratti and V. criceti (Marchandin et al., 2005), differed by only $1 \%$ of their $16 \mathrm{~S}$ rRNA gene nucleotide positions. Several other species, such as $V$. rogosae and $V$. parvula (Arif et al., 2008), as well as $V$. atypica and $V$. dispar or $V$. parvula (Marchandin et al., 2003), displayed no more than $2 \%$ of rrs sequence divergence. Housekeeping genes, considered as single-copy genes, are thought to overcome limitations due to $16 \mathrm{~S}$ rRNA gene heterogeneity (Dahllöf et al., 2000). Previously used for taxonomic purposes in the genus Veillonella, the $r p o B$ gene was used to structure the population of Veillonella spp.; isolates were affiliated to taxonomically relevant clades according to the rpoB-based phylogeny. Intragenomic $16 \mathrm{~S}$ rRNA gene V3 region heterogeneity was observed in all the $r p o B$ clades, with heterogeneity levels of $\leqslant 1 \%$ observed for $V$. dispar and $V$. atypica clades and heterogeneity levels ranging from $>1$ to $2.5 \%$ reported for the six other clades. Thus, intragenomic $(0.5-2.5 \%)$ and intraspecific $(0.5-3 \%) \mathrm{V} 3$ heterogeneity may be as high as interspecific divergence $(1-7.5 \%)$ of the whole $16 \mathrm{~S}$ rRNA gene and may impair 16S rDNA-based identification of closely related species in the genus Veillonella. As previously described for Veillonella sp. strain ADV 360.1, which shows $1.43 \%$ rrs heterogeneity, or for Aeromonas veronii strain LMG13695, which shows $1.52 \%$ divergence between copies, such high levels of intragenomic heterogeneity may also confuse phylogeny (Marchandin et al., 2003; Morandi et al., 2005). Finally, high levels of intragenomic heterogeneity raise the problem of the bacterial species delineation. Stackebrandt \& Ebers (2006) have recently proposed to raise the threshold of $97 \%$ of $r r s$ identity previously retained for species delineation (Stackebrandt \& Goebel, 1994) to $98.7 \%$ (Stackebrandt \& Ebers, 2006). For an $r r s$ heterogeneity level $>1.3 \%$, the existence of novel taxa could be erroneously suggested. Intragenomic $16 \mathrm{~S}$ rRNA gene heterogeneities could also affect diversity studies, leading to an overestimation of the number of different clones in studied samples. PCR-TTGE used for studying the bacterial diversity in different communities (Muyzer, 1999; Roudière et al., 2009) could also be used for preliminary testing of known important bacteria of the community in order to avoid diversity overestimation due to $r r s$ heterogeneity or to artefactual bands, with the aim to propose appropriate correction factors for diversity studies.

Heterogeneity between rrs copies in the genus Veillonella may be attributed to mutations after gene duplication or to horizontal $r r n$ transfer (Yap et al., 1999; van Berkum et al., 2003), followed by a lack of intragenomic concerted evolution (Santoyo \& Romero, 2005). Rupture in concerted evolution could occur if heterogeneity conferred a selective advantage to the bacteria. These heterogeneities previously demonstrated for other bacteria belonging to human microflora (Satokari et al., 2001; Vásquez et al., 2001; Roudière et al., 2007) could have a function in the adaptation to the environment of these bacteria and in maintaining their diversity in human or other mammal microflora (López-López et al., 2007; Jensen et al., 2009).

\section{ACKNOWLEDGEMENTS}

The authors are very grateful to Dr Hélène Jean-Pierre from the Anaerobe Laboratory of the University Hospital in Montpellier for her help in forming the collection of clinical isolates and to Dr JeanPhilippe Carlier for the gift of $V$. parvula CIP 60.1 and $V$. denticariosi CIP 109449 strains.

\section{REFERENCES}

Aas, J. A., Paster, B. J., Stokes, L. N., Olsen, I. \& Dewhirst, F. E. (2005). Defining the normal bacterial flora of the oral cavity. J Clin Microbiol 43, 5721-5732.

Acinas, S. G., Marcelino, L. A., Klepac-Ceraj, V. \& Polz, M. F. (2004). Divergence and redundancy of $16 \mathrm{~S}$ rRNA sequences in genomes with multiple rrn operons. J Bacteriol 186, 2629-2635.

Adilakshmi, T., Ramaswamy, P. \& Woodson, S. A. (2005). Proteinindependent folding pathway of the $16 \mathrm{~S}$ rRNA 5' domain. J Mol Biol 351, 508-519.

Arif, N., Do, T., Byun, R., Sheehy, E., Clark, D., Gilbert, S. C. \& Beighton, D. (2008). Veillonella rogosae sp. nov., an anaerobic, Gram negative coccus isolated from dental plaque. Int J Syst Evol Microbiol 58, 581-584. 
Bhatti, M. A. \& Frank, M. O. (2000). Veillonella parvula meningitis: case report and review of Veillonella infections. Clin Infect Dis 31, 839-840.

Boo, T. W., Cryan, B., O’Donnell, A. \& Fahy, G. (2005). Prosthetic valve endocarditis caused by Veillonella parvula. J Infect 50, 81-83.

Byun, R., Carlier, J.-P., Jacques, N. A., Marchandin, H. \& Hunter, N. (2007). Veillonella denticariosi sp. nov., isolated from human carious dentine. Int J Syst Evol Microbiol 57, 2844-2848.

Case, R. J., Boucher, Y., Dahllöf, I., Holmström, C., Doolittle, W. F. \& Kjelleberg, S. (2007). Use of $16 \mathrm{~S}$ rRNA and $r p o B$ genes as molecular markers for microbial ecology studies. Appl Environ Microbiol 73, 278-288.

Cilia, V., Lafay, B. \& Christen, R. (1996). Sequence heterogeneities among $16 \mathrm{~S}$ ribosomal RNA sequences, and their effect on phylogenetic analyses at the species level. Mol Biol Evol 13, 451-461.

Coenye, T. \& Vandamme, P. (2003). Intragenomic heterogeneity between multiple $16 \mathrm{~S}$ ribosomal RNA operons in sequenced bacterial genomes. FEMS Microbiol Lett 228, 45-49.

Conville, P. S. \& Witebsky, F. G. (2007). Analysis of multiple differing copies of the $16 \mathrm{~S}$ rRNA gene in five clinical isolates and three type strains of Nocardia species and implications for species assignment. J Clin Microbiol 45, 1146-1151.

Dahllöf, I., Baillie, H. \& Kjelleberg, S. (2000). rpoB-based microbial community analysis avoids limitations inherent in 16S rRNA gene intraspecies heterogeneity. Appl Environ Microbiol 66, 3376-3380.

Favier, C. F., Vaughan, E. E., De Vos, W. M. \& Akkermans, A. D. (2002). Molecular monitoring of succession of bacterial communities in human neonates. Appl Environ Microbiol 68, 219-226.

Felsenstein, J. (1997). An alternating least squares approach to inferring phylogenies from pairwise distances. Syst Biol 46, 101-111.

Graf, J. (1999). Diverse restriction fragment length polymorphism patterns of the PCR-amplied 16S rRNA genes in Aeromonas veronii strains and possible misidentication of Aeromonas species. J Clin Microbiol 37, 3194-3197.

Guindon, S. \& Gascuel, O. (2003). A simple, fast, and accurate algorithm to estimate large phylogenies by maximum likelihood. Syst Biol 52, 696-704.

Hall, T. A. (1999). BioEdit: a user-friendly biological sequence alignment editor and analysis program for Windows 95/98/NT. Nucleic Acids Symp Ser 41, 95-98.

Huson, D. H. \& Bryant, D. (2006). Application of phylogenetic networks in evolutionary studies. Mol Biol Evol 23, 254-267.

Janse, I., Bok, J. \& Zwart, G. (2004). A simple remedy against artifactual double bands in denaturing gradient gel electrophoresis. J Microbiol Methods 57, 279-281.

Jensen, S., Frost, P. \& Torsvik, V. L. (2009). The nonrandom microheterogeneity of $16 \mathrm{~S}$ rRNA genes in Vibrio splendidus may reflect adaptation to versatile lifestyles. FEMS Microbiol Lett 294, 207215.

Könönen, E., Kanervo, A., Takala, A., Asikainen, S. \& JousimiesSomer, H. (1999). Establishment of oral anaerobes during the first year of life. J Dent Res 78, 1634-1639.

López-López, A., Benlloch, S., Bonfá, M., Rodríguez-Valera, F. \& Mira, A. (2007). Intragenomic $16 \mathrm{~S}$ rDNA divergence in Haloarcula marismortui is an adaptation to different temperatures. J Mol Evol 65, 687-696.

Marchandin, H., Jean-Pierre, H., Carrière, C., Canovas, F., Darbas, H. \& Jumas-Bilak, E. (2001). Prosthetic joint infection due to Veillonella dispar. Eur J Clin Microbiol Infect Dis 20, 340-342.

Marchandin, H., Teyssier, C., Siméon de Buochberg, M., JeanPierre, H., Carrière, C. \& Jumas-Bilak, E. (2003). Intra-chromosomal heterogeneity between the four 16S rRNA gene copies in the genus Veillonella: implications for phylogeny and taxonomy. Microbiology 149, 1493-1501.

Marchandin, H., Teyssier, C., Jumas-Bilak, E., Robert, M., Artigues, A.-C. \& Jean-Pierre, H. (2005). Molecular identification of the first human isolate belonging to the Veillonella ratti-Veillonella criceti group based on $16 \mathrm{~S}$ rDNA and dnaK gene sequencing. Res Microbiol 156, 603-607.

Marriott, D., Stark, D. \& Harkness, J. (2007). Veillonella parvula discitis and secondary bacteremia: a rare infection complicating endoscopy and colonoscopy? J Clin Microbiol 45, 672-674.

Martínez-Murcia, A. J., Antón, A. I. \& Rodríguez-Valera, F. (1999). Patterns of sequence variation in two regions of the $16 \mathrm{~S}$ rRNA multigene family of Escherichia coli. Int J Syst Bacteriol 49, 601610.

Morandi, A., Zhaxybayeva, O., Gogarten, J. P. \& Graf, J. (2005). Evolutionary and diagnostic implications of intragenomic heterogeneity in the 16S rRNA gene in Aeromonas trains. J Bacteriol 187, 65616564.

Moreno, C., Romero, J. \& Espejo, R. T. (2002). Polymorphism in repeated $16 \mathrm{~S}$ rRNA genes is a common property of type strains and environmental isolates of the genus Vibrio. Microbiology 148, 12331239.

Muyzer, G. (1999). DGGE/TGGE a method for identifying genes from natural ecosystems. Curr Opin Microbiol 2, 317-322.

Neefs, J. M., Van de Peer, Y., De Rijk, P., Chapelle, S. \& De Wachter, R. (1993). Compilation of small ribosomal subunit RNA structures. Nucleic Acids Res 21, 3025-3049.

Ninet, B., Monod, M., Emler, S., Pawlowski, J., Metral, C., Rohner, P., Auckenthaler, R. \& Hirschel, B. (1996). Two different $16 \mathrm{~S}$ rRNA genes in a mycobacterial strain. J Clin Microbiol 34, 2531-2536.

Nübel, U., Engelen, B., Felske, A., Snaidr, J., Wieshuber, A., Amann, R. I., Ludwig, W. \& Backhaush, H. (1996). Sequence heterogeneities of genes encoding 16S rRNAs in Paenibacillus polymyxa detected by temperature gradient gel electrophoresis. J Bacteriol 178, 5636-5643.

Ogier, J. C., Son, O., Gruss, A., Tailliez, P. \& Delacroix-Buchet, A. (2002). Identification of the bacterial microflora in dairy products by temporal temperature gradient gel electrophoresis. Appl Environ Microbiol 68, 3691-3701.

Paster, B. J., Boches, S. K., Galvin, J. L., Ericson, R. E., Lau, C. N., Levanos, V. A., Sahasrabudhe, A. \& Dewhirst, F. E. (2001). Bacterial diversity in human subgingival plaque. J Bacteriol 183, 3770-3783.

Preza, D., Olsen, I., Aas, J. A., Willumsen, T., Grinde, B. \& Paster, B. J. (2008). Bacterial profiles of root caries in elderly patients. J Clin Microbiol 46, 2015-2021.

Roudière, L., Lorto, S., Tallagranda, E., Marchandin, H., Jeannot, J.-L. \& Jumas-Bilak, E. (2007). Empreinte moléculaire des communautés bactériennes et hétérogénéité intraspécifique de l'ADNr 16S: est-il raisonnable d'occulter le problème? Pathol Biol (Paris) 55, 434-440 (in French).

Roudière, L., Jacquot, A., Marchandin, H., Aujoulat, F., Devine, R., Zorgniotti, I., Jean-Pierre, H., Picaud, J.-C. \& Jumas-Bilak, E. (2009). Optimized PCR-temporal temperature gel electrophoresis compared to cultivation to assess diversity of gut microbiota in neonates. J Microbiol Methods 79, 156-165.

Santoyo, G. \& Romero, D. (2005). Gene conversion and concerted evolution in bacterial genomes. FEMS Microbiol Rev 29, 169-183.

Satokari, R. M., Vaughan, E. E., Akkermans, A. D. L., Saarela, M. \& De Vos, W. M. (2001). Bifidobacterial diversity in human feces detected by genus-specific PCR and denaturing gradient gel electrophoresis. Appl Environ Microbiol 67, 504-513. 
Stackebrandt, E. \& Ebers, J. (2006). Taxonomic parameters revisited: tarnished gold standards. Microbiol Today 33, 152-155.

Stackebrandt, E. \& Goebel, B. M. (1994). Taxonomic note: a place for DNA-DNA reassociation and $16 \mathrm{~S}$ rRNA sequence analysis in the present species definition in bacteriology. Int J Syst Bacteriol 44, 846849.

Sundquist, A., Bigdeli, S., Jalili, R., Druzin, M. L., Waller, S., Pullen, K. M., El-Sayed, Y. Y., Taslimi, M. M., Batzoglou, S. \& Ronaghi, M. (2007). Bacterial flora-typing with targeted, chip-based Pyrosequencing. BMC Microbiol 7, 108.

Teyssier, C., Marchandin, H., Siméon de Buochberg, M., Ramuz, M. \& Jumas-Bilak, E. (2003). Atypical $16 \mathrm{~S}$ rRNA gene copies in Ochrobactrum intermedium strains reveal a large genomic rearrangement by recombination between rrn copies. J Bacteriol 185, 29012909.

Thompson, J. D., Gibson, T. J., Plewniak, F., Jeanmougin, F. \& Higgins, D. G. (1997). The CLUSTAL_X windows interface: flexible strategies for multiple sequence alignment aided by quality analysis tools. Nucleic Acids Res 25, 4876-4882.

Ueda, K., Seki, T., Kudo, T., Yoshida, T. \& Kataoka, M. (1999). Two distinct mechanisms cause heterogeneity of $16 \mathrm{~S}$ rRNA. J Bacteriol 181, 78-82. van Berkum, P., Terefework, Z., Paulin, L., Suomalainen, S., Lindström, K. \& Eardly, B. D. (2003). Discordant phylogenies within the rrn loci of Rhizobia. J Bacteriol 185, 2988-2998.

Vásquez, A., Ahrné, S., Pettersson, B. \& Molin, G. (2001). Temporal temperature gradient gel electrophoresis (TTGE) as a tool for identication of Lactobacillus casei, Lactobacillus paracasei, Lactobacillus zeae and Lactobacillus rhamnosus. Lett Appl Microbiol 32, 215-219.

Wang, M., Ahrné, S., Antonsson, M. \& Molin, G. (2004). T-RFLP combined with principal component analysis and $16 \mathrm{~S}$ rRNA gene sequencing: an effective strategy for comparison of fecal microbiota in infants of different ages. J Microbiol Methods 59, 53-69.

Yap, W. H., Zhang, Z. \& Wang, Y. (1999). Distinct types of rRNA operons exist in the genome of the actinomycete Thermomonospora chromogena and evidence for horizontal transfer of an entire rRNA operon. J Bacteriol 181, 5201-5209.

Zilberstein, B., Quintanilha, A. G., Santos, M. A., Pajecki, D., Moura, E. G., Alves, P. R., Maluf Filho, F., de Souza, J. A. \& Gama-Rodrigues, J. (2007). Digestive tract microbiota in healthy volunteers. Clinics 62, 47-54.

Zuker, M. (2003). Mfold web server for nucleic acid folding and hybridization prediction. Nucleic Acids Res 31, 3406-3415.

Edited by: W. Liesack 